\title{
Traumatic Symmetric Biparietal Extradural Hematoma: Report of Two Cases
}

\author{
G. Lakshmi Prasad ${ }^{1}$ Sumit Sinha ${ }^{1}$ \\ ${ }^{1}$ Department of Neurosurgery, All India Institute of Medical \\ Sciences, New Delhi, India \\ Indian J Neurosurg 2017;6:126-128.
}

\begin{abstract}
Address for correspondence Dr. Sumit Sinha, MCh, Room 307, JPNATC, All India Institute of Medical Sciences, Raj Nagar, New Delhi, India (e-mail: sumitneuro@gmail.com).
\end{abstract}
Abstract
Keywords
- extradural hematoma
- biparietal
- symmetric
- mirror image

Traumatic bilateral epidural hematomas (EDHs) are uncommon and are mostly found in the frontal region because of extension of fracture across the midline and tear of venous sinus. Authors report two cases of mirror image biparietal extradural hematoma after sustaining a high-velocity motor vehicle accident. Both were adult males and had a very low admission GCS of less than 8. Emergency hematoma evacuation was performed bilaterally and good outcomes were achieved in both. Mean follow-up duration was 9 months. The pathophysiologic mechanisms are different from solitary EDH as are the clinical features and outcomes. The rarity of these lesions and surgical nuances are highlighted.

\section{Introduction}

Among bilateral extradural hematomas (EDH), bifrontal EDH is the most common. Symmetrical biparietal EDH is extremely rare with only a handful of cases reported. ${ }^{1-4}$ Authors report two such cases.

\section{Case 1}

A 60 -year-old man was brought after being hit by a car. On assessment, his Glasgow coma scale (GCS) was 4/15. Pupils were asymmetric with sluggish reaction. Computed tomography (CT) scan showed large symmetrical biparietal EDH with small right basal ganglia hematoma (-Fig. 1a). Emergency evacuation was performed with bilateral craniotomies in prone position. Postoperative scan showed no residual hematoma (- Fig. $\mathbf{1 b}$ ). He gradually improved and was doing well at last follow-up of 1 year.

\section{Case 2}

A 30-year-old man was brought to emergency department after a road accident. His GCS was 7/15. Left pupil was dilated and unresponsive. CT scan showed symmetrical biparietal EDH with bilateral frontal contusions ( - Fig. 2a). With patient supine, bilateral parietal craniotomies and evacuation was performed. No residual hematoma was noted on postoperative

received

March 28, 2015

accepted after revision

January 18, 2016

published online

April 12, 2017 scan ( - Fig. 2b). He recovered gradually and was doing well at 6 months follow-up.

The exact pathophysiologic mechanism of bilateral EDH is unclear, but various theories have been postulated. The direction of force tends to be anteroposterior than lateral and dura is detached from two sites by a single force. ${ }^{4}$ Further stripping of dura mater can occur due to extension of the fracture across the midline, which is most commonly seen in bifrontal and bilateral posterior fossa EDH. ${ }^{2}$ Also, they can occur because of similar coup and contra-coup injuries.

Bilateral EDHs are different from solitary EDHs. They are often associated with significant trauma, have low GCS on admission, lesser frequency of lucid interval, and evolve rapidly. Rapid deterioration and high mortality rates are other differentiating features. ${ }^{1,5}$-Table 1 summarizes the reported cases.

Emergency surgical evacuation is mandatory. The side of surgery depends on the hematoma volume. With similar volumes bilaterally, craniotomy and evacuation need to be performed on both sides, initially on the dominant side or simultaneously by two groups of neurosurgeons. ${ }^{1,4}$ Agrawal suggested bilateral craniotomies and sequential evacuation. ${ }^{4} \mathrm{~A}$ nonoperative approach might be followed for small-volume hematomas. To conclude, symmetric biparietal EDH is a rare occurrence. Most of them have low GCS on admission. Emergency bilateral craniotomies and evacuation of hematoma should be performed. Majority have good outcomes.
License terms of India

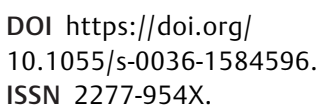

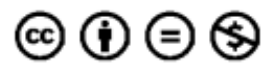




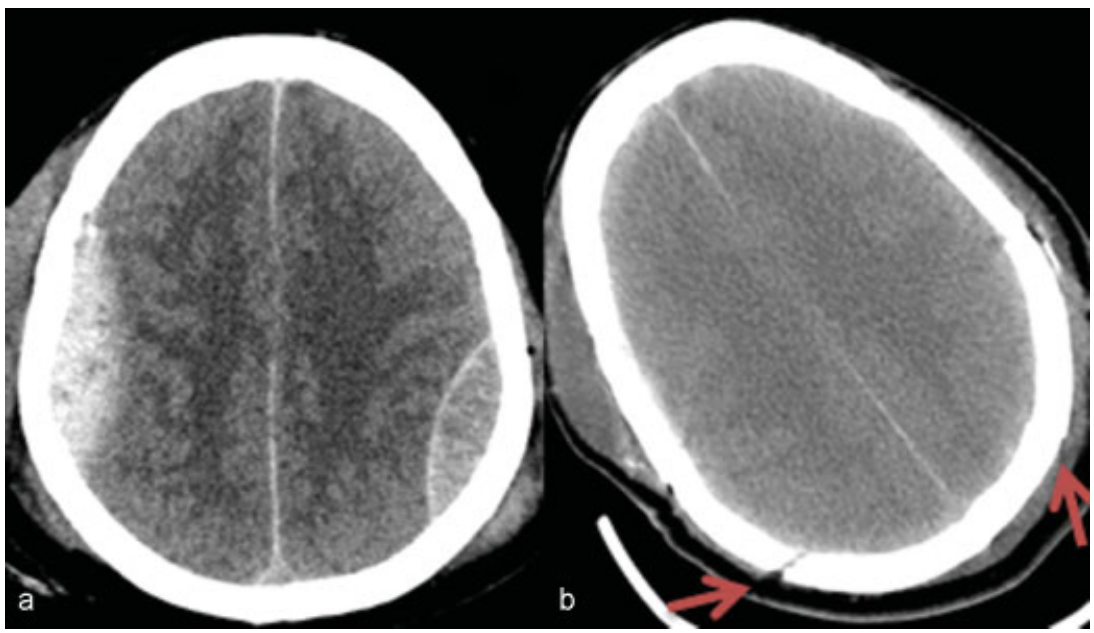

Fig. 1 Preoperative CT showing mirror image biparietal acute EDH (a). Postoperative CT showing evidence of bilateral parietal craniotomies (arrows) and complete evacuation of hematoma (b).

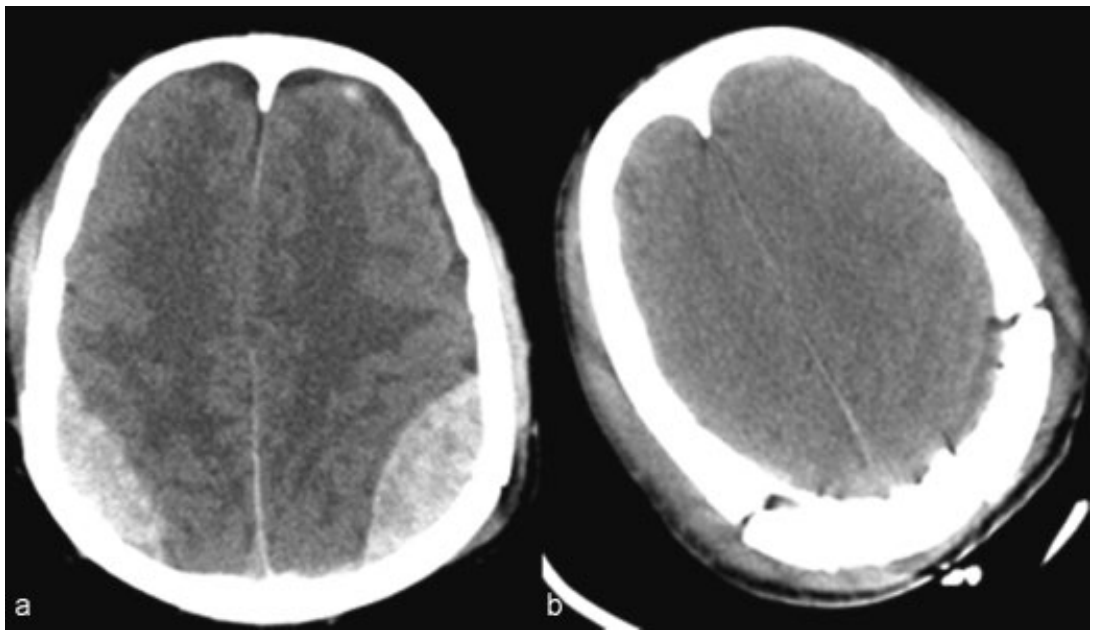

Fig. 2 Noncontrast CT done at admission showing symmetric biparietal acute EDH (a). Postoperative CT showing bilateral parietal craniotomies with no residual hematoma (b).

Table 1 Literature review of traumatic symmetric biparietal extradural hematomas

\begin{tabular}{|c|c|c|c|c|c|c|}
\hline Author (reference) & $n$ & Age/ex & Mode of injury & GCS & Treatment & Final outcome (GCS) \\
\hline Agrawal $^{4}$ & 1 & $55 / F$ & Fall of object & 9 & Surgery $\mathrm{B} / \mathrm{L}$ & Good (15) \\
\hline Idei et al $^{1}$ & 1 & $72 / \mathrm{M}$ & Fall & NA & Surgery B/L & Good (15) \\
\hline Ramzan et $\mathrm{al}^{2}$ & 2 & $\begin{array}{l}N A^{a} \\
N A^{a}\end{array}$ & $\begin{array}{l}\text { NA } \\
\text { NA }\end{array}$ & $\begin{array}{l}14 \\
8\end{array}$ & $\begin{array}{l}\text { Surgery } B / L \\
\text { Surgery } B / L\end{array}$ & $\begin{array}{l}\text { Good (15) } \\
\text { Fair (12) }\end{array}$ \\
\hline Udoh $^{3}$ & 2 & $\begin{array}{l}64 / M \\
60 / M\end{array}$ & $\begin{array}{l}\text { RTA } \\
\text { RTA }\end{array}$ & $\begin{array}{l}11 \\
7\end{array}$ & $\begin{array}{l}\text { Left-surgery; right-resolved } \\
\text { Surgery B/L }\end{array}$ & $\begin{array}{l}\text { Good (15) } \\
\text { Died }\end{array}$ \\
\hline Prasad (present) & 2 & $\begin{array}{l}60 / \mathrm{M} \\
30 / \mathrm{M}\end{array}$ & $\begin{array}{l}\text { RTA } \\
\text { RTA }\end{array}$ & $\begin{array}{l}4 \\
7\end{array}$ & $\begin{array}{l}\text { Surgery } \mathrm{B} / \mathrm{L} \\
\text { Surgery } \mathrm{B} / \mathrm{L}\end{array}$ & $\begin{array}{l}\text { Good (15) } \\
\text { Good (15) }\end{array}$ \\
\hline
\end{tabular}

Abbreviations: B/L, bilateral; F, female; GCS, Glasgow coma scale; M, male; NA, not available; $n$, number of cases; RTA, road traffic accident. aExact age not specified but has been mentioned as adults. 


\section{Note}

This article has not been presented at any meeting earlier.

Conflicts of Interest

None.

\section{Financial Disclosures}

None.

\section{Contribution of Authors}

G.L.P. was responsible for conceptualization, design of manuscript, and data collection. S.S. was responsible for manuscript supervision. Both the authors have approved the article.

\section{References}

1 Idei M, Shima T, Nishida $M$, et al. Symmetrical bilateral epidural hematoma after head injury in the mid parietooccipital region: case report [in Japanese]. No Shinkei Geka 2004; 32(4):379-382

2 Ramzan A, Wani A, Malik AH, Kirmani A, Wani MA. Acute bilateral extradural hematomas. Neurol India 2002;50(2): 217-219

3 Udoh DO. Bilateral post-traumatic acute extradural hematomas: a report of four cases and review of literature. Niger J Clin Pract 2012;15(1):104-107

4 Agrawal A. Bilateral symmetrical parietal extradural hematoma. J Surg Tech Case Rep 2011;3(1):34-36

5 Huda MF, Mohanty S, Sharma V, Tiwari Y, Choudhary A, Singh VP. Double extradural hematoma: an analysis of 46 cases. Neurol India 2004;52(4):450-452 